\title{
Revisão por pares e produtivismo acadêmico sob a ótica de avaliadores de artigos de periódicos em Administração
}

\author{
Peer Review and Academic Productivism from the View \\ of Reviewers of Academic Journals in Management
}

\section{Revisión por pares y productivismo académico desde la óptica de evaluadores de artículos de revistas en Administración}

http://dx.doi.org/10.21713/2358-2332.2016.v13.960

Helena Belintani Shigaki, doutoranda em Administração no Centro de Pós-Graduação e Pesquisa em Administração da Faculdade de Ciências Econômicas da Universidade Federal de Minas Gerais (UFMG), Belo Horizonte, MG, Brasil. E-mail: belintanihs@gmail.com.

Roberto Patrus, doutor em Filosofia pela Universidad Complutense de Madrid - Espanha, professor do programa de mestrado e doutorado em Administração da Pontifícia Universidade Católica de Minas Gerais (PUC Minas), Belo Horizonte, MG, Brasil. E-mail: robertopatrus@pucminas.br.

\section{Resumo}

Em uma cultura de produtivismo, marcada pela valorização da publicação de artigos científicos, o tema da revisão por pares ganha relevância. $\mathrm{O}$ objetivo deste estudo foi refletir sobre como o produtivismo é visto pelos avaliadores de artigos científicos da área de Administração, sob a luz de três objetivos específicos: identificar as motivações e influências externas do porquê professores atuam como revisores, entender sua avaliação acerca do sistema de revisão por pares no Brasil, e identificar as possiveis causas por eles atribuídas ao produtivismo. A abordagem do estudo foi qualitativa tendo como procedimento básico a análise de conteúdo de 11 entrevistas com avaliadores experientes. Os resultados 
apontam mais críticas que elogios à revisão por pares, recomendações de aperfeiçoamento e a associação entre a avaliação da Capes com o produtivismo.

Palavras-chave: Revisão por Pares. Produtivismo Acadêmico. Avaliadores. Periódicos.

\section{Abstract}

In a productivist culture, marked by the appreciation of the publication of scientific papers, the subject of peer review becomes relevant. The aim of this study was to reflect on how productivism is seen by the reviewers of scientific papers in the area of Administration, in the light of three specific objectives: to identify the motivations and external influences that teachers act as reviewers, to understand their assessment about the peer review system in Brazil, and to identify the possible causes for them assigned to productivism. The approach of the study was qualitative, having as basic procedure the content analysis of 11 interviews with expert reviewers. The results show more criticism than praise for peer review, improvement recommendations and the association between the evaluation of Capes and productivism.

Keywords: Peer review. Academic Productivity. Reviewers. Journals.

\section{Resumen}

En una cultura de productivismo, que tiene la marca de la valorización de la publicación de artículos científicos, el tema de la revisión por pares es relevante. El objetivo de este estudio ha sido reflexionar sobre cómo el productivismo es visto por los evaluadores de artículos científicos del área de Administración, a la luz de tres objetivos específicos: identificar las motivaciones e influencias externas de las razones que llevan los profesores a actuar como evaluadores, comprender su apreciación sobre el sistema de revisión por pares en Brasil, e identificar las posibles causas por ellos atribuidas al productivismo. El abordaje del estudio es cualitativo, 
el procedimiento básico es el análisis de contenido de once entrevistas con evaluadores expertos. Los resultados apuntan más críticas que elogios a la revisión por pares, recomendaciones de perfeccionamiento y la asociación entre la evaluación de la Capes e el productivismo.

Palabras clave: Revisión por Pares. Productivismo Académico. Evaluadores. Revistas.

\section{INTRODUÇão}

Em uma cultura de produtivismo acadêmico, marcada pela valorização da publicação de artigos científicos, o tema da avaliação desses artigos, feita por pares, ganha relevância fundamental. Se o processo de peer review, como é chamado na língua inglesa, não for criterioso e de qualidade, toda a construção de uma academia que valoriza a publicação se fragiliza, passando a ter o que Mattos (2012) chamou de "pés de barro".

Entende-se a revisão por pares, neste artigo, como um processo sistemático constituído por dois ou mais avaliadores, com vista a obter imparcialidade na avaliação, por meio da leitura e análise dos artigos submetidos. A partir destes procedimentos, fornecer um parecer, com contribuições e comentários aos autores (BORBA; MURCIA, 2006; BOTOMÉ, 2011; CAMPANARIO, 2002; MEDIA, 2008; STUMPF, 2008). Esse processo viabiliza a publicação do artigo em periódico, um dos produtos finais esperados de uma pesquisa científica. A ênfase nesse tipo de produção tem levado vários pesquisadores brasileiros e estrangeiros a falarem em uma cultura do produtivismo acadêmico.

No Brasil, esta cultura na pós-graduação começou a ser inserida no final dos anos 1970 e foi legitimada nos anos 1990 (GODOl; XAVIER, 2012). É considerada como uma influência dos procedimentos avaliativos da Capes aos programas de mestrado e doutorado (MOREIRA, 2009; ROSA, 2008). Segundo Moreira (2009), ela transforma o processo de conhecimento em mercadoria, limitando-o a produtos em níveis de desempenho e padrões de qualidade. Com frequência, a constante pressão por publicação atormenta os docentes da pós-graduação, contribuindo 
para que o desempenho dos professores seja medido pelo produto final (GODOI; XAVIER, 2012; MOREIRA, 2009). Neste sentido, esse modelo de avaliação vem intensificando o trabalho docente, com prejuízo da saúde física e mental dos pesquisadores (BIANCHETTI; MACHADO, 2009; GODOI; XAVIER, 2012).

Como objetivo geral deste estudo, cabe refletir como essa ânsia produtivista é vista pelos avaliadores de artigos de revistas científicas da área de Administração. E, como objetivos específicos, responder às seguintes questões: por que o avaliador se dispõe a avaliar artigos de periódicos? Qual a avaliação dele acerca do sistema de revisão por pares no Brasil? Quais são as causas por ele atribuídas ao produtivismo acadêmico?

\section{REVISÃO POR PARES}

A comunicação das atividades de pesquisa não começou com as revistas. No tempo da revolução científica, ela se fazia predominantemente por cartas entre os pesquisadores. A evolução das formas de intercâmbio que alimentam a atividade científica esteve intimamente ligada às condições materiais de circulação de cartas e impressos (GABLOT, 1984; ZUCKERMAN; MERTON, 1971). No século XVII, as correspondências entre cientistas desenvolveram-se graças aos serviços postais. Paralelamente, os primeiros periódicos, tais como o Journal des Sçavans, na França, e o Philosophical Transactions, da Royal Society, na Inglaterra, foram criados em 1665. Contrariamente às correspondências que se desenvolviam livremente, certa ordem se estabeleceu graças à publicação de periódicos, reafirmando o caráter público dessa comunicação. Observa-se neste momento, a gênese do processo de avaliação da ciência (DANTAS, 2014; GABLOT, 1984; ZUCKERMAN; MERTON, 1971).

Apesar de o sistema de revisão por pares ser amplamente utilizado (KOSTOFF, 1996) e aceito pela academia, ultimamente, ele tem sido alvo de várias críticas, na maioria dos casos, motivadas pelas distorções de seu uso (HAMES, 2012; OMOTE, 2005; PESSANHA, 1998; WARE, 2008). As críticas mais genéricas, segundo Hames (2012), dão conta (a) de que a avaliação por pares estaria "em crise", (b) de que seria melhor "publicar 
tudo e filtrar mais tarde", (c) de que o sistema está sujeito a injustiças, (d) de que as normas de avaliação não são claras, (e) de que o processo não está imune a idiossincrasias, como abusos e preconceitos por parte de editores e revisores, (f) de que sua lentidão de avaliação provoca atrasos na publicação, (g) de que o processo é pobre na detecção de erros, (h) de que é quase inútil na detecção de fraudes e má conduta, (i) de que é caro e trabalhoso, e (j) de que os revisores estão sobrecarregados, trabalhando voluntariamente e sujeitos a falhas, mesmo nas melhores revistas.

A avaliação por pares auxilia os editores a decidirem quais artigos são adequados para seus periódicos e ajuda os autores a melhorarem a qualidade dos seus trabalhos (PATRUS; DANTAS; SHIGAKI, 2013). Esse sistema pode ser utilizado de quatro formas distintas: (a) single blind review (revisão cega unilateral), na qual a identidade do avaliador é desconhecida, mas a do autor não; (b) double blind review (revisão cega bilateral), que denota uma avaliação na qual nem o avaliador nem o autor se conhecem, mas o editor conhece ambas as partes; (c) total blind review, na qual nenhuma das partes tem acesso às identidades, seja dos autores, avaliadores ou editores; e (d) open review, que, embora pouco utilizada, se constitui em uma avaliação na qual todas as partes têm acesso às identidades.

Uma vez debatido o tema da revisão por pares, passemos à questão do produtivismo acadêmico.

\section{PRODUTIVISMO ACADÊMICO}

O produtivismo acadêmico, ou performatividade acadêmica, pode se caracterizar como uma "[...] uma ênfase exacerbada na produção em grande quantidade de algo que possui pouca substância [...]" (ALCADIPANI, 2011b, p. 1174). Trata-se de uma "[...] tecnologia, uma cultura e um modo de regulação que se serve de críticas, comparações e exposições como meio de controle, pressão e mudança [...]" (BALL, 2002, p. 3). Recentemente, diferentes compreensões críticas deste fenômeno têm sido trabalhadas por pesquisadores brasileiros e estrangeiros (ALCADIPANI, 2011a, 2011b; FREITAS, 2011; GODOI; XAVIER, 2012; LEITE et al., 2011; 
MASCARENHAS; ZAMBALDI; MORAES, 2011; MATTOS, 2012, 2008; MELLO; CRUBELLATE; ROSSONI, 2009; MOREIRA, 2009; ROSA, 2008; SALO; HEIKKINEN, 2011; TREIN; RODRIGUES, 2011), e apesar de já ter sido claramente diagnosticado há mais de uma década, os estudos são recentes e poucos são empíricos.

O termo produtivismo vem sendo utilizado de forma ampla em artigos brasileiros, e poucos são aqueles que fazem uso do termo performatividade acadêmica. No entanto, Macedo (2015) defende seu uso, ao dizer que, "em vez dos termos produtivismo ou império do Lattes [...]" (p.775), utiliza "[...] o conceito de cultura performativa, visando a evitar o tom pejorativo que pouco ajuda na análise política do momento atual" (p. 755). Neste artigo, optou-se pelo uso do termo produtivismo acadêmico. O uso do sufixo "ismo" marca a posição teórica dos autores que reconhecem a importância da produtividade acadêmica e de uma performance compativel com universidades de excelência, mas criticam a ênfase exacerbada em apenas uma das dimensões do fazer acadêmico: a necessária publicação científica.

A cultura do produtivismo acadêmico no Brasil está fortemente associada a mudanças introduzidas no processo de avaliação dos cursos de pós-graduação stricto sensu da Capes, por causa da adoção de uma metodologia quantitativa (MOREIRA, 2009) nos processos de regulação e controle (ROSA, 2008; SGUISSARDI, 2010). Com isso, houve um salto na produção acadêmica em Administração, medido em termos de quantidade (BERTERO; CALDAS; WOOD, 1999). Hoje, o termo é assimilado a uma fábrica de fazer pontos (GODOI; XAVIER, 2012), como um feticheconhecimento-mercadoria, que influencia o "mal-estar" da academia (TREIN; RODRIGUES, 2011).

Em busca de maior produtividade, o fazer acadêmico é racionalizado quando se criam sistemas de gerenciamento próximos à lógica industrial (ROSA, 2008). O desempenho passa a ser medido em resultados palpáveis e cada vez mais o professor-pesquisador se vê julgado em razão do número de artigos que escreve (MOREIRA, 2009). Essa cultura tornou-se também mundialmente conhecida pela expressão publish or perish (publicar ou perecer), significando que os "[...] professores/pesquisadores que não 
publicassem de acordo com os parâmetros postos como ideais pelos órgãos financiadores, pela burocracia universitária ou pelo mercado, veriam sua carreira definhar e fenecer" (SGUISSARDI, 2010). Nesta dinâmica, o trabalho mais valioso é o mais recente e o acesso a este de forma veloz se transforma em um diferencial para o sucesso de um pesquisador (CARVALHO; MANOEL, 2006).

Em contraposição a essa abordagem crítica do produtivismo, Macedo (2015) defende a ideia de que no Brasil a realidade é ainda muito diferente do que vem ocorrendo na cultura acadêmica americana, em que há rankings internacionais de universidades que valorizam números de ex-alunos e docentes vencedores do prêmio Nobel, de medalha Field, de pesquisadores com alto nível de citações, artigos indexados na Science Citation Index - SCl, e artigos dos periódicos Nature e Science. Já Schwartzman (2013) reconhece que o uso de indicadores de avaliação de artigos é um problema do produtivismo quando passa a ser mais importante do que realmente deveria avaliar ou indicar, ou seja, importando somente a quantidade e não a qualidade. 0 mesmo autor menciona outros problemas/riscos, a saber: nem sempre os melhores pesquisadores são aqueles que publicam muito; concentração de pesquisa nos principais centros de publicação; valorização da pesquisa acadêmica em detrimento dos trabalhos aplicados e, também, da pesquisa pública em relação à industrial.

Verifica-se, também, um "desfile de assuntos repetidos" (FREITAS, 2011, p. 1160) com consequente crescimento de publicações que jamais foram ou serão utilizados em outras pesquisas (ALMEIDA; GUIMARÃES; ALVES, 2010), os chamados junk papers (artigos ruins) (GODOI; XAVIER, 2012). O problema com esses autores é que eles acreditam que quanto mais publicações com seu nome, maior a chance de conseguirem autoqualificação (MATTOS, 2008), prestígio e benefícios tão almejados pelas IES. E estes não deixam de ter razão. Passam a contribuir, então, com um ciclo atípico, que mantém o produtivismo (GODOI; XAVIER, 2012). No entanto, "[...] entre publicar ou perecer, alguns pesquisadores têm optado pela segunda alternativa" (PATRUS; LIMA, 2012, p. 8), abandonando a carreira em programas de pós-graduação. 
Parece evidente que o atual sistema seja indutor de um círculo nada virtuoso (RODRIGUES, 2007). Estimula-se o professor que mais produz em termos quantitativos em detrimento daquele que produz pouco, mas com qualidade (RODRIGUES, 2007). À medida que o número de publicação é maximizado, os projetos passam a ter prazos apertados e metas cada vez mais rigorosas. 0 monitoramento do desempenho se tornou, desde então, um mecanismo estratégico para os programas que apostam no domínio tecnológico como meio de ampliar suas reservas econômicas e obter acesso a bens e serviços (SGUISSARDI, 2006). A publicação se tornou, também, uma condição para obtenção de financiamento de pesquisas e certos benefícios, como bolsa produtividade, melhores notas no ranking da pós-graduação, prestígio junto aos pares, participação em congressos, entre outros (RODRIGUES, 2007; TREIN; RODRIGUES, 2011).

A partir da revisão da literatura, foram encontradas 15 possíveis consequências da cultura do produtivismo: (a) intensificação do trabalho docente (BIANCHETTI; MACHADO, 2009; GODOI; XAVIER, 2012); (b) orientação tática do programa para os critérios e indicadores que têm maior peso na avaliação da Capes (MACCARI et al., 2008); (c) dificuldade em encontrar professores dispostos a assumir cargos administrativos, orientar alunos ou participar de comitês da universidade (NASCIMENTO, 2010); (d) (de) formação na produção da nova geração de pesquisadores (GODOI; XAVIER, 2012); (e) "McDonaldização" das atividades docentes (ALCADIPANI, 2011b, SALO HEIKKINEN, 2011, p. 1); (f) publicações repetidas ou maquiadas (KUENZER; MORAES, 2005); (g) prejuízo da saúde física e mental dos pesquisadores (BIANCHETTI; MACHADO, 2009); (h) plágio e autoplágio (TREIN; RODRIGUES, 2011); (i) ênfase na dimensão mercantil do conhecimento (TREIN; RODRIGUES, 2011); (j) fetiche da citação (MATTOS, 2012); (k) desonestidade nas publicações (RODRIGUES, 2007); (I) criação de um clima de terror nas IES (MOREIRA, 2009); (m) má qualidade nas publicações (ALCADIPANI, 2011a, 2011b; MATTOS, 2008; MOREIRA, 2009); (n) aumento de coautoria (LEITE et al., 2011); e (o) criação da lógica do empilhamento (GODOI; XAVIER, 2012).

São poucos os autores que trabalham o viés positivo do produtivismo acadêmico. Dentre eles, podem ser citados o artigo de Macedo (2015) e de Schwartzman (2013). Macedo (2015) descreve 
produtivismo como "[...] a indução para publicação com vistas a atender às expectativas das agências de fomento e, com isso, garantir financiamento" (p. 755). Defende, ainda, sob argumentos de outros autores como Ball (2002) e Velho (1997), que há recompensa e satisfação para alguns pesquisadores, bem como se mostra uma competição saudável para a comunidade. E ainda, que diante do aumento da criação de cursos de doutorado (em educação) no Brasil e da demanda dos alunos, é natural que a produção bibliográfica também aumente.

Schwartzman (2013), em um texto publicado em seu blog com o título "publicar ou morrer", defende a ideia de que não há nada de errado com o produtivismo, que "[...] cientistas e pesquisadores precisam ser avaliados por sua produtividade, e que essa produtividade se expressa em produtos tangíveis - artigos, patentes e outros - é correta. Não há dúvida de que ela coloca os pesquisadores sob tensão, mas isso é parte da vida" (p. 1). Nosso posicionamento, já apresentado anteriormente, defende que o problema não está na necessidade de publicar, tampouco na avaliação da produtividade do pesquisador, mas no "-ismo" da produtividade, que exacerba o seu valor, obnubila outras competências importantes do professor permanente de um programa de pós-graduação e, ainda, dá mais valor à quantidade de pontos das publicações classificadas no Qualis do que a sua qualidade e utilidade.

Como possíveis alternativas para conter essa cultura de produtivismo, há duas soluções que poderiam ser levadas em consideração: (a) redistribuição da pontuação das atividades dos professores e (b) o cumprimento das exigências da avaliação da Capes sem levá-las ao absurdo, a fim de desenvolver um projeto de pós-graduação autônomo, que persiga metas próprias com vistas à produção de conhecimento. Assim, "o compromisso maior da pesquisa deveria ser produzir e elevar conhecimentos para a melhoria da vida individual e coletiva em suas múltiplas dimensões e interfaces [...]" (FREITAS, 2011, p. 1160).

\section{MÉTODO}

Esse estudo é de abordagem qualitativa, compreendida por seus elementos dotados de significados, motivos, aspirações e valores, em 
um espaço complexo de relações (MINAYO; DESLANDES; NETO; GOMES, 1999), assim como o objetivo da pesquisa. É do tipo exploratório, pela possibilidade de descoberta (GODOI; BALSINI, 2004), de se familiarizar com o fenômeno estudado (POUPART et al., 2002), e também pela geração de contribuições teóricas a partir da confrontação dos dados coletados com a literatura já existente (EISENHARDT, 1989).

Com a intenção de localizar quais professores seriam entrevistados, todos os sites de periódicos em Administração A1 e A2 foram visitados, e as informações sobre os avaliadores formaram uma base de dados. Posteriormente, os avaliadores foram escolhidos pela localização e também pela experiência como avaliador, medida em anos.

Em relação à quantidade de entrevistados, optou-se pela utilização de dois critérios, mutuamente excludentes: (a) em relação à quantidade propriamente dita e (b) a partir da saturação empírica, ou seja, quando não há incidências de novas ideias ou informações por parte dos entrevistados (GIBBS, 2009). Alguns autores argumentam que, para uma pesquisa qualitativa, é suficiente atingir o número de 6 a 12 entrevistados (PAAVILAINEN; ASTEDT, 1997; PARTIS, 2003). Outros indicam entrevistar o maior número de pessoas possíveis, a fim de ora obter diversidade nas informações (GODOI; BANDEIRA-DE-MELLO; SILVA, 2007), ora obter saturação empírica (POUPART et al., 2002).

Com base nesses critérios, foram entrevistados 11 professores. Eles foram convidados a participar dessa pesquisa por e-mail, feito pelos próprios autores, e também pela técnica snowball(bola de neve), pela qual um entrevistado indica o outro em caráter sucessivo (AABOEN; FRIDA LIND, 2012). As entrevistas, com duração média de 47 minutos, foram realizadas pessoalmente, com exceção de uma via Skype (aplicativo de comunicação on-line). Todas foram gravadas, mediante autorização dos entrevistados, transcritas e analisadas. Por ser a transcrição considerada uma mudança de meio (da fala para a escrita), estas foram realizadas pelos próprios autores, mantendo assim a precisão, fidelidade e interpretação das informações (GIBBS, 2009). Foram entrevistados 9 homens e 2 mulheres, que apresentaram uma experiência como avaliadores que variou de 5 a 21 anos. Todos participam de avaliações de periódico nível A e a grande 
maioria também dos de nível B. A quantidade de artigos avaliados, por avaliador, varia de 4 a 21 por ano.

Para análise dos dados, foi utilizada a técnica de análise de conteúdo, visto que possibilita a construção de informações a partir dos dados coletados e consequentemente o estabelecimento de tendências sociais e o enfoque sistemático. A análise foi detalhada logo a seguir.

O roteiro de entrevista, não estruturado, foi elaborado à luz da revisão de literatura realizada neste artigo, com vistas a identificar e analisar os métodos e critérios de avaliação dos entrevistados, bem como analisar sua percepção acerca do contexto de produtividade acadêmica. 0 roteiro de poucas perguntas permitiu aos entrevistados oferecer respostas mais profundas sobre o assunto pesquisado (SANDERS, 1982) e ao entrevistador a flexibilidade para ordenar e formular as perguntas de acordo com o andamento de cada entrevista (GODOI; BANDEIRA-DEMELLO; SILVA, 2007).

Realizou-se uma leitura detalhada de todas as transcrições das entrevistas, com a intenção de estabelecer um plano de análise. Portanto, cada objetivo específico foi organizado de modo a permitir essa categorização, conforme se observa na Figura 1.

Figura 1. Detalhamento da análise dos dados

\begin{tabular}{c|c|c|c|c}
\hline \multicolumn{2}{c|}{ Momento 1 (M1) } & \multicolumn{3}{c}{ Momento 2 (M2) } \\
\hline Etapa 1 & Etapa 2 & Etapa 3 & Etapa 4 & Etapa 5 \\
\hline $\begin{array}{c}\text { Identificação } \\
\text { das citações } \\
\text { para cada } \\
\text { objetivo } \\
\text { específico }\end{array}$ & $\begin{array}{c}\text { Organização } \\
\text { das citações }\end{array}$ & $\begin{array}{c}\text { Identificação } \\
\text { dos códigos } \\
\text { descritivos }\end{array}$ & $\begin{array}{c}\text { Identificação } \\
\text { das categorias }\end{array}$ & $\begin{array}{c}\text { Identificação } \\
\text { dos códigos } \\
\text { analíticos }\end{array}$ \\
\hline
\end{tabular}

Fonte: Elaborado pelos autores

O M1 se iniciou com a identificação das citações de cada entrevistado para cada objetivo específico, Etapa 1. Isto ocorreu por meio da leitura detalhada das entrevistas. A organização destas citações, ou preparação do material, realizou-se posteriormente, Etapa 2, e cada 
entrevista passou pelo mesmo processo de alinhamento de enunciados e proposições (BARDIN, 2011).

As três últimas etapas, presentes no $\mathrm{M} 2$, foram realizadas de forma criteriosa. Na Etapa 3, houve a inclusão de uma palavra-chave ou código descritivo (GIBBS, 2009) para cada citação de cada entrevistado. Esse código descritivo estava, em muitos casos, presente na própria fala do entrevistado e foi utilizado neste estudo para promover a identificação e o estabelecimento das categorias e códigos analíticos. Nos casos em que não estava presente, um código descritivo novo foi utilizado a partir de trechos das falas, como o uso do código "critérios pessoais", espelho das palavraschave "trabalhos empíricos", "merece ser publicado", "posso aprender algo novo", entre outros. Ou seja, todas as palavras do texto podem se tornar um código descritivo, formando assim uma primeira unidade de registro (BARDIN, 2011) e consequentemente um novo reagrupamento. Na Etapa 4, após a identificação e análise das diferenças e similaridades entre os códigos descritivos, houve o ajuste correto das categorias, que foram novamente agrupadas. Já na Etapa 5, esses novos grupos suscitaram os códigos analíticos (GIBBS, 2009) ou unidade de contexto (BARDIN, 2011). Esse último código foi utilizado para a compreensão das mensagens e a exata significação da escolha dos códigos descritivos e categorias (BARDIN, 2011).

\section{ANÁLISE DOS DADOS}

A análise dos dados se dividiu em três partes, que correspondem respectivamente a cada um dos objetivos específicos da pesquisa: por que o avaliador se dispõe a avaliar artigos de periódicos, qual a avaliação dele acerca do sistema de revisão por pares no Brasil e, quais são as causas por ele atribuídas ao produtivismo acadêmico.

\subsection{Por que você avalia?}

Dentre as tantas possibilidades que motivam um professor a ser avaliador de artigos, seis foram identificadas neste estudo e classificadas 
na ordem decrescente de citações: (a) trabalho voluntário, (b) obter conhecimento e inspiração, (c) ganhar pontos, (d) contribuir com o artigo, (e) exigência da Capes e do programa, e (f) status. A análise destas motivações permite classificá-las entre motivações intrínsecas e estímulos externos (Figura 2).

\section{Figura 2. Motivações e estímulos externos dos revisores}

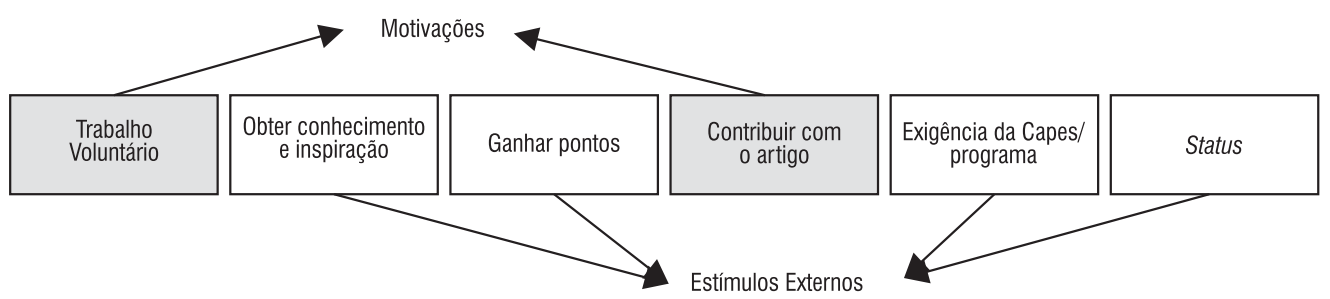

Fonte: Elaborado pelos autores, com dados da pesquisa.

O fato de ser um trabalho voluntário e de ter a possibilidade de contribuir, anonimamente, com o artigo de um pesquisador, também anônimo, são motivações para os avaliadores. Já a possibilidade de obter conhecimento e inspiração para novos projetos, ganhar pontos, status e participar do sistema por ser uma exigência da Capes e do programa são os estímulos externos, ou seja, feito com o intuito de receber uma recompensa ou, em último caso, de não receber uma punição.

Os entrevistados, em grande parte, compreendem a importância em fazer parte do sistema com seu trabalho voluntário, em contribuir com o andamento e aperfeiçoamento do sistema e do próprio artigo recebido e, em alguns casos, o trabalho pode ser até considerado como gracioso. Estes "porquês" foram os únicos apontados como motivação, partindo da necessidade interna de participação e cooperação com o todo, da mutualidade de interesses e deveres com os pares e da construção e difusão do conhecimento. Dessa forma, os avaliadores são reconhecidos aqui, por eles mesmos, como voluntários e essa auto-nomeação auxilia no aumento do rigor e da validade do conhecimento (CAMPANARIO, 2002).

Por outro lado, os entrevistados acreditam que, ao revisarem um artigo, eles também serão beneficiados com novos conhecimentos, poderão ter inspirações em seus próprios trabalhos e até mesmo receber alguns pontos pelo trabalho realizado. Para este último, corroborando a 
lógica de Godoi e Xavier (2012) e Santos (2004), os avaliadores passam a se preocupar com a lógica do sistema e, consequentemente, cria-se um círculo dialético, no qual o professor se preocupa, principalmente, com as atividades que somam ponto, e o programa de pós-graduação reconhece e premia esse esforço, que, por sua vez, será também reconhecido e premiado pela agência reguladora.

Os que fazem a avaliação dos artigos por se tratar, simplesmente, de uma exigência da Capes, vista como uma agência de regulação e controle (SGUISSARDI, 2006), ou do próprio programa de Pós-Graduação em Administração (PPGA), fazem para não receberem uma punição e não serem excluídos do sistema.

Esse dado vai ao encontro do pensamento de Rosa (2008) acerca do papel da pressão institucional, no qual o professor "anormal" é transformado em professor "normal" para ser inserido no programa de recompensas institucionais (melhoria do conceito do programa, ganho de recursos e atração de novos talentos) e não recebe mais as punições (tal como o descredenciamento do programa). Também segue o mesmo viés da ideia de Maccari et al. (2008), de que os programas, devido à má interpretação do sistema, possuem orientações táticas para os critérios e indicadores com maior peso na Capes, e a produção intelectual é um deles (35\%). Por fim, está de acordo com um estudo realizado por Shigaki e Patrus (2012), em que todas as IES brasileiras foram investigadas quanto às avaliações da Capes e no qual foi comprovado que IES com maior nota não necessariamente são as que publicam mais, e as que publicam mais não necessariamente possuem notas altas. A fala do Entrevistado A reflete essa realidade: "você está me entrevistando só porque eu sou revisor, eu tenho um poder aí. Não ganha dinheiro, não ganha nada, mas ganha uns pontinhos pro ego [...] meu auto-afago. [Entrevistado A]".

Por último, tem-se o status como um dos motivos que leva o professor a participar deste sistema, que traz à tona um fator que foi discutido aqui como uma causa do produtivismo: a competição. Ou seja, novamente há um novo ciclo virtuoso, coadunando com Moreira (2009) e Miller (2006), segundo o qual, para garantir ou manter o prestígio ou status de um avaliador, a competição é incentivadora, com isso, novamente 
se volta à necessidade de elevação do status para obter distinção e um pseudo-reconhecimento.

\subsection{0 que você acha do sistema de revisão por pares?}

As falas dos entrevistados foram analisadas e as críticas ao sistema de avaliação por pares se sobressaíram em relação aos elogios. As críticas mais comuns, aqui elencadas em ordem decrescente de citações, estão relacionadas a tempo, sobrecarga de trabalho, subjetividade das avaliações, falta de reconhecimento do trabalho do avaliador, falta de padrão de qualidade na seleção dos avaliadores, necessidade de ter mais avaliadores para criar rotatividade entre eles, parcialidade dos editores e abuso de poder. Essas críticas confirmam as pesquisas de Botomé (2011), Campanario (2002), Hames (2012), Kostoff (1996), Kruger (2005), Media (2008), Omote (2005), Pessanha (1998), Pinho (2005), Serra, Fiates e Ferreira (2008), Thiry-Cherques (2005) e Ware (2008). É interessante mencionar que a competição, crítica apontada por Meneghini e Fonseca (1990) foi mencionada nas entrevistas como uma causa do produtivismo, mas não com viés negativo ou de crítica. Na Figura 3, as críticas e os elogios estão organizados graficamente e em ordem de quantidade de citações dos entrevistados.

Figura 3. Críticas e elogios ao sistema de revisão por pares
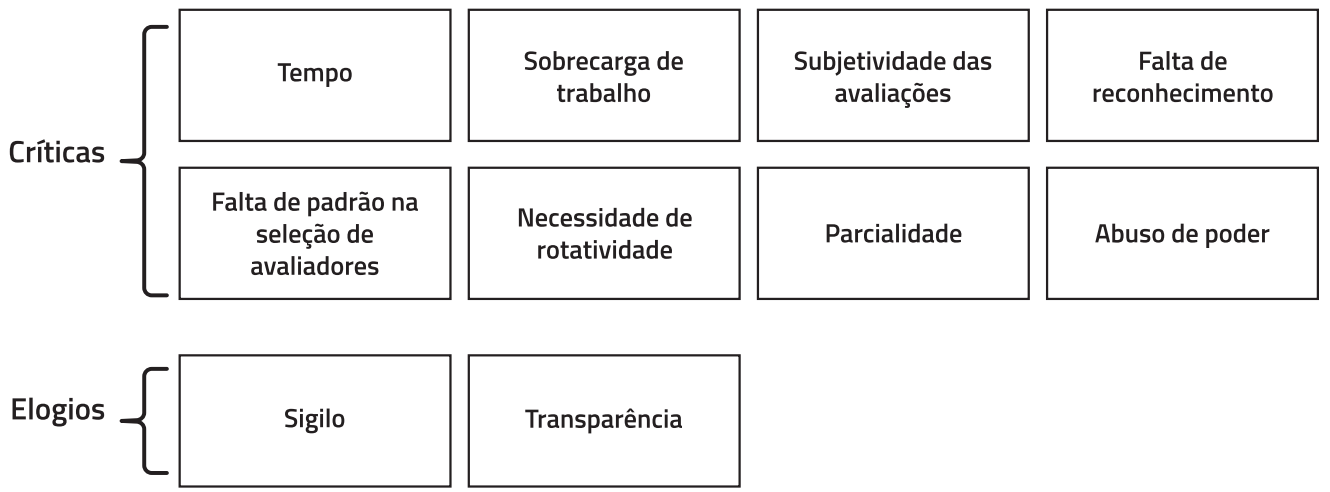

Transparência

Fonte: Elaborado pelos autores, com dados da pesquisa.

Embora o trabalho seja voluntário, em muitos casos não há como cumprir o prazo preestabelecido pelo periódico. Ao perguntar aos entrevistados o tempo efetivo de trabalho para avaliação de um artigo, 
houve uma variação de 30 minutos a 20 horas, que são distribuídas ao longo de alguns dias, conforme disponibilidade do avaliador. $O$ desempenho de um avaliador, bem como a qualidade do artigo que é desenvolvido, está relacionado ao tempo. Conforme Pinho (2005), por ser um trabalho voluntário, muitas vezes o avaliador posterga esta tarefa que demanda tempo para ser realizada, corroborando o pensamento de Stumpf (2008).

A sobrecarga de trabalho, evidenciada pela pressão a que 0 avaliador está sujeito ao assumir múltiplas tarefas, foi uma crítica muito mencionada nas entrevistas. Mas muitos trabalham em prol da melhoria do sistema com vistas à contribuição e ao fato de se voluntariar, o que poderia diminuir essa sobrecarga psicológica e possibilitar ao professor deixar de ser julgado em razão de número, contradizendo Moreira (2009).

A crítica à subjetividade pode ser interpretada com base na IES ou no avaliador. No entanto, foram mencionadas apenas aquelas com foco no avaliador, que, por intermédio de sua experiência, fornece uma avaliação ou um parecer com "a sua cara", muitas vezes por falta de treinamento, o que confirma o argumento de Botomé (2011). Essa subjetividade pode, entre tantas outras consequências, provocar julgamentos negativos em favorecimento próprio ou injustiça. Uma tentativa de minimizá-la é o treinamento, conforme sugerem Serra, Fiates e Ferreira (2008).

A falta de reconhecimento do trabalho do avaliador pela instituição de ensino se vincula ao sistema de avaliação da Capes, em que essa atividade, apesar de fundamental, não é pontuada. Para Santos (2004), o que não é possível de ser mensurado deixa de ter importância, confirmando argumento de Nascimento (2010) e Trein e Rodrigues (2011) quanto à dificuldade de encontrar professores para assumir cargos administrativos e de participar de orientações e outras avaliações.

A falta de qualidade na seleção dos avaliadores e a necessidade de rotatividade desses são críticas de causa e consequência. Da mesma forma que há dificuldade em prospectar avaliadores qualificados e interessados, há dificuldade em criar a rotatividade desses. 0 número de publicações aumenta de forma contínua e esse aumento com a falta de mão de obra prejudica o desenvolvimento e aperfeiçoamento do sistema, gerando 
sobrecarga de trabalho para os avaliadores existente e as $n$ consequências tratadas na literatura. Por isso, há o fenômeno de dependência dos atuais avaliadores, conforme afirmam Mulligan, Hall e Raphael (2013). Para exemplificar, "toda revista deveria ter um rol muito grande desses revisores para não ficar viciado. Eu lembro que teve uma revista que mandou 6 ou 7 artigos para eu revisar. [Entrevistado F]".

A última crítica mencionada nas entrevistas se refere ao abuso de poder do editor e consequentemente à parcialidade na seleção e no julgamento. Embora não tenha sido mencionado o abuso quanto à seleção dos avaliadores, o que contradiz Campanario (2002) e Pinho (2005). Há parcialidade nas primeiras avaliações (desk review) e no veto à avaliação final (desk rejection), coadunando com Stumpf (2008). Esse poder pode ser devido ao acesso às informações privilegiadas, o que confere uma falha na transparência do sistema e no modelo utilizado, corroborando Lee e Bero (2006).

As demais críticas mencionadas no estudo teórico, como preconceito, competição, dificuldades em detectar erros e fraudes e aquelas sobre o custo das avaliações, não foram mencionadas, direta ou indiretamente, pelos entrevistados.

Os elogios referem-se, principalmente, ao sigilo e à transparência. Ao contrário da literatura estudada, a falta de sigilo é considerada uma crítica ao sistema de peer review, embora pouco mencionada e comprovada nos estudos de Ware (2008), a partir do acesso às informações privilegiadas, afirmado por Campanario (2002). E a transparência é um dos pontos que precisa ser melhorado no sistema (LEE; BERO, 2006).

Tendo em vista que as críticas se sobressaltaram, grande parte dos entrevistados pensou em novas sugestões para tentativa de melhoria do sistema. No entanto, ainda há aqueles que não conseguem visualizar uma melhoria.

Quanto às sugestões, fez-se quatro: duas relacionadas ao avaliador e duas ao próprio formato que é utilizado hoje, o double blind review. As duas sugestões para melhoria do avaliador, seja em sua contratação, seja em sua motivação, podem ser ilustradas na Figura 4. 
Figura 4. Sugestões para melhoria do revisor
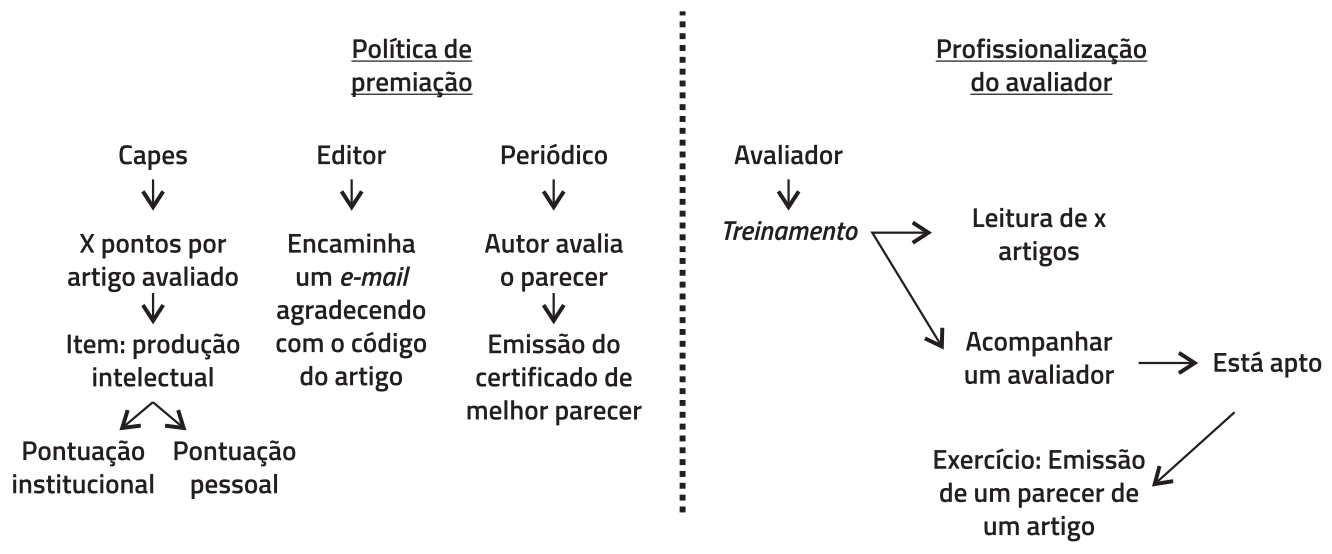

Fonte: Elaborado pelos autores, com dados da pesquisa.

A política de premiação para o avaliador foi muito mencionada durante as entrevistas, mas não a remuneração salarial, pois isso poderia encarecer todo o sistema e mercantilizá-lo ainda mais. A remuneração simbólica poderia vir da Capes, do editor ou da própria política do periódico. A remuneração pela Capes seria por meio de pontos. A cada avaliação realizada e comprovada, o avaliador ganharia $x$ pontos, que poderiam ser destinados ao programa, para melhoria da nota na avaliação trienal e ou ao próprio professor, no item de produção técnica. A remuneração pelo editor é mais simples, um e-mailcom um agradecimento e o código do artigo para ser colocado no Lattes seria satisfatório. Já a remuneração pelo periódico consiste na emissão de um certificado de melhor avaliador, a cada nova edição da revista. Os avaliadores seriam julgados pelos próprios autores, que tiveram seus artigos aprovados.

Outra proposta feita pelos entrevistados foi a profissionalização do avaliador, que consiste em melhorar o processo de seleção dos avaliadores, podendo em médio ou longo prazo aumentar a qualidade dos pareceres. 0 avaliador convidado ou inscrito no periódico passaria por três etapas de treinamento: leitura de $n$ artigos sobre revisão por pares e métodos de avaliação. Posteriormente acompanhar um avaliador em uma avaliação, e o avaliador tutor indicar se o avaliador treinado está apto ou não a continuar a profissionalização. Neste caso, ele poderá fazer um exercício: emitir um parecer para um artigo. Esta sugestão se coaduna com a sugestão de Patrus, Dantas e Shigaki (2013) com a proposição de um treinamento 
virtual similar ao que é realizado atualmente no Academy of Management. Com isso, a política de "tentativa e erro" desprezada por Yaffe (2009) seria de fato abandonada. As duas sugestões de melhoria, feitas pelos entrevistados, estão ilustradas na Figura 5.

\section{Figura 5. Sugestões para melhoria do processo de revisão por pares}
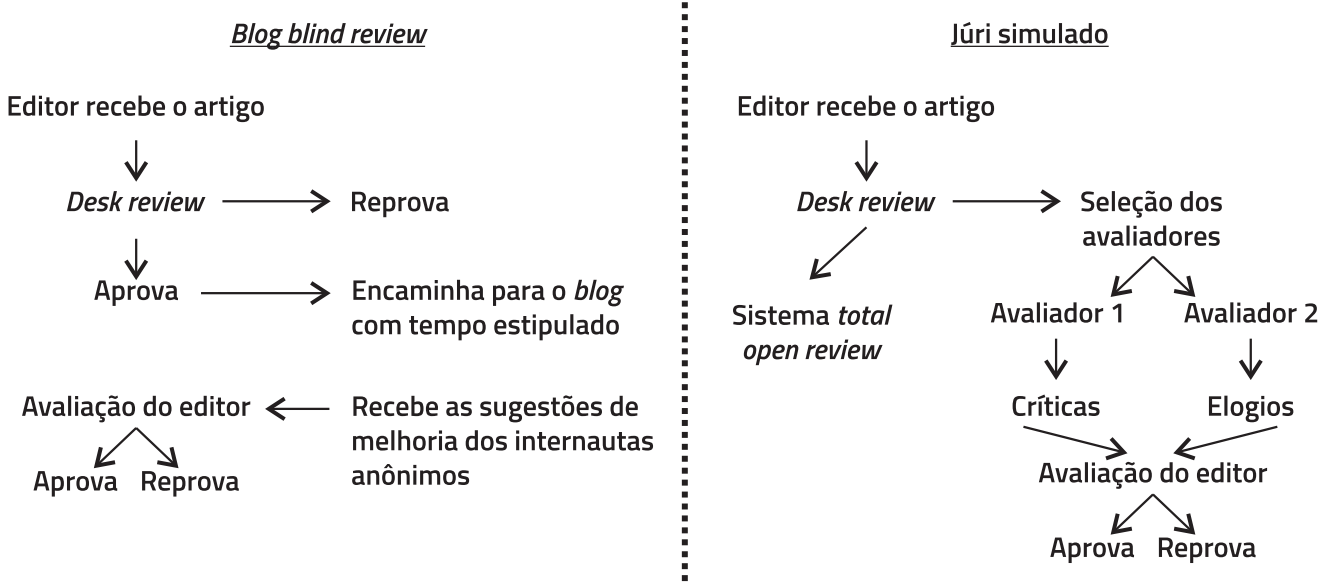

Fonte: Elaborado pelos autores, com dados da pesquisa.

A primeira sugestão de melhoria é uma alternativa de informatização do sistema, por meio do blog blind review, para melhoria do tempo de resposta dos avaliadores, até então a principal crítica. Apesar de o atual sistema ser elogiado, as críticas se destacam e consequentemente a tentativa de sua melhoria. Para isso, os artigos seriam recebidos pelo editor em processo double blind review e julgados em desk review. Se aprovado, o artigo passa para a segunda fase, na qual o editor faz o upload do artigo no blog do periódico, estipula um prazo limite para avaliação e convida a comunidade a contribuir. Encerrado esse prazo, o editor julgará novamente as contribuições e aprovará ou reprovará. Como há um maior número de avaliadores, a chance de um rápido retorno é maior, sem dúvidas. Mas problemas como parcialidade ou falta de ética dos avaliadores podem vir a acontecer.

A segunda sugestão, feita por um entrevistado, é um júri simulado que se inicia com o editor. Da mesma forma, ele realiza um desk review e, a partir dessa primeira avaliação, convida os avaliadores que podem, de fato, contribuir com o estudo. Esse processo seria total open review e para isso o editor promoveria um sorteio entre os avaliadores, sendo um 
responsável por encontrar pontos positivos e outro os pontos negativos, minimizando as chances de abuso de poder do avaliador. Posteriormente, o editor medirá os comentários e decidirá se o artigo está aprovado ou reprovado.

Embora o sistema de avaliação esteja instituído na academia há muitos anos, surge aos poucos a necessidade de mudança, visando à garantia de qualidade dos artigos publicados bem como de melhoria da condição de trabalho do avaliador.

\subsection{Quais as causas do produtivismo?}

Para os entrevistados, a cultura do produtivismo está se enraizando na academia. Ao estudar as causas desta nova cultura, os entrevistados apontam: (a) o processo de construção da ciência, do conhecimento, (b) da necessidade de se "produzir até se chegar a um diamante", (c) da competição entre os professores e, finalmente, (d) a Capes.

Curiosamente, os mesmos professores que insinuam que avaliam pela pontuação, status, poder, exigências externas, são os mesmos professores que contribuem mencionando que a causa do produtivismo é a competição e a Capes. Por outro lado, aqueles que avaliam de forma voluntária, para contribuir com o andamento do sistema e com o artigo recebido, mencionam que a causa está em fazer ciência e produzir um grande conhecimento a partir da quantidade.

Ainda nesta lógica de contribuição, há um ponto de vista que merece ser estudado. Um entrevistado, contrário às argumentações de que se vive em um contexto produtivista, mencionou que o "produtivismo" é visto de forma positiva para ele. Por esse fato, pode-se pensar no prazer do avaliador em participar desse sistema, contribuir com o aumento e padronização do rigor das avaliações e consequentemente na qualidade das publicações, o que corrobora o estudo de Campanario (2002). Desta forma, a lógica de mal-estar na academia é minimizada pela satisfação no trabalho, conforme Moreira (2009). 
Em relação ao fato da competição, ela aparece como uma causa predadora, em que um é melhor que o outro, na necessidade de se ganharem mais pontos que seu concorrente/colega de trabalho, em ser bolsista produtividade, em ter estagiários. A lógica da competitividade acadêmica está em obter prestígio e statusneste sistema já mercantilizado, afirmado por Freitas (2011) e Miller (2006).

Por último, tem-se o sistema de avaliação da Capes como uma das principais causas do produtivismo. A cobrança para que o professor produza sempre mais, normalmente vem do programa que recebe "ordens" da própria Capes. Esta pressão institucional provoca mudanças na rotina dos professores, por isso gera queixas na concepção de Mattos (2008).

As motivações e os estímulos externos para participar de um processo de avaliação, advêm ou, em alguns casos, contribuem para a manutenção das causas desse sistema produtivista, o que deste modo é visto de forma negativa por alguns e positiva por outros, por meio das críticas e elogios, mas poucos são aqueles que visualizam um sistema melhor para se trabalhar.

Como discutido na revisão de literatura, o produtivismo tem causas relacionadas à Capes e, consequentemente, aos programas de pós-graduação por ela avaliados, que fomentam a participação no sistema de revisão por pares. Essa participação pode ocorrer tanto por meio de uma lógica colaborativa por parte dos professores (aqueles que se sentem motivados para avaliar), quanto por uma lógica utilitária (aqueles que avaliam em resposta a estímulos externos).

\section{CONSIDERAÇÕES FINAIS}

A revisão por pares se situa, em meio à cultura do produtivismo acadêmico, com o papel de garantir qualidade aos trabalhos que são publicados (BORBA; MURCIA, 2006; BOTOMÉ, 2011; CAMPANARIO, 2002; STUMPF, 2008). No entanto, um sistema cheio de falhas sofre algumas retaliações, embora sejam poucas as sugestões de melhorias. Apontadas neste estudo, as possiveis melhorias para este sistema se relacionam a 
dois pontos principais: melhoria no que tange ao avaliador e à avaliação em si. Ao avaliador, sugere-se um processo de profissionalização e também de remuneração simbólica. À avaliação, um sistema total open review por meio de um júri simulado e ao mesmo tempo um sistema blind review informatizado.

A necessidade de treinamento e de remuneração é latente, seja na literatura estudada, seja nos dados coletados. A partir deste treinamento, poder-se-á pensar na padronização do sistema, minimizando assim as várias críticas e, quem sabe, também o mal-estar na academia. Também mencionada várias vezes, os avaliadores prezam a remuneração simbólica, um reconhecimento do esforço feito. 0 júri simulado possui uma visão de objetividade e transparência do sistema e já o sistema informatizado a rapidez. Cabe aqui aprofundar o estudo nessa perspectiva exploratória e diagnosticar se tais propostas de melhorias aqui apontadas são condizentes de fato, com o atual sistema de revisão por pares no contexto de produtivismo, como o sistema e os próprios autores envolvidos (editores, revisores e autores) podem se adaptar a essas mudanças e o quanto serão benéficas em curto e em longo prazo.

Por fim, as causas do produtivismo na visão dos avaliadores são a necessidade de se fazer ciência, de produzir muito até conseguir um resultado de qualidade, a competição e, novamente, a pressão da avaliação da Capes. A Capes vem sendo citada como uma agência reguladora e a principal influenciadora deste fenômeno de produtivismo, conciliado com o aspecto de competição, que consequentemente gera um pseudoreconhecimento, muitas vezes inexistente, ao avaliador. Já as causas relacionadas à produção de conhecimento e à publicação em larga escala em benefício da sociedade fazem refletir sobre a existência de professores com foco na contribuição e consequente rigor de avaliações, o que gera qualidade das publicações por se tratar de um trabalho colaborativo e voluntário. E o mais importante, o professor, nesse caso, tem claro em sua mente seu papel na comunidade. Estes foram os principais achados da pesquisa, e, sendo a avaliação uma parte integrante da atividade acadêmica, o sistema de revisão por pares deveria existir em função da cientificidade, agregado às normas básicas de ética (FREITAS, 2011). 
Em resumo, os resultados encontrados exaltam a necessidade de se pensar na melhoria do sistema de revisão por pares, com foco na visão do programa e do avaliador quanto a seu papel na academia. Os dados recebidos apontaram ricas contribuições ao tema revisão por pares e produtivismo acadêmico a partir da visão do avaliador, confirmando estudos realizados, quantitativamente, no exterior e indicando as possiveis diferenças culturais quanto à avaliação. Espera-se que esta pesquisa sirva de base para futuros estudos e que o tema aqui abordado possa ser estudado sob o viés do editor, do programa de Pós-Graduação e da própria Capes.

Assim, sugere-se também explorar os seguintes pressupostos: (a) o que não é possível de ser mensurado deixa de ter importância para o sistema de avaliação (ALCADIPANI, 2011a, 2011b; SANTOS, 2004), (b) os programas de pós-graduação tendem a demonstrar interesse no planejamento de atividades que se relacionam diretamente com os indicadores de avaliação (ALCADIPANI, 2011a, 2011b; MOREIRA, 2009; NASCIMENTO, 2010; SANTOS, 2004), (c) a quantidade de publicações se tornou mais importante que a sua qualidade (KIRSCHIBAUM; PORTO; FERREIRA, 2004; NASCIMENTO, 2010) e (d) como a competição e a busca por status, consideradas causas para a manutenção do produtivismo, influenciam e influenciaram o sistema de revisão por pares ao longo dos anos.

\section{Referências}

AABOEN, L.; FRIDA LIND, A.D.Capturing processes in longitudinal multiplecase studies. Industrial Marketing Management, Estados Unidos, v.41, n.2, p. 235-246, 2012.

ALCADIPANI, R. Academia e a fábrica de sardinhas. Organizações \& Sociedade, Salvador, v.57, n.18, p. 345-348, 2011 a.

ALCADIPANI, R. Resistir ao produtivismo: uma ode à perturbação acadêmica. Cadernos Ebape.br, Rio de Janeiro, v.9, n.4, p. 1174-1178, 2011b. 
ALMEIDA, E.C.E; GUIMARÃES, J.A.; ALVES, I.T.G. Dez anos do portal de periódicos da Capes: histórico, evolução e utilização. Revista Brasileira de Pós-Graduação, Brasília, v.7, n.13, p. 218-246, 2010.

BALL, S. Reformar escolas/reformar professores e os terrores da performatividade. Revista Portuguesa de Educação, Braga, v.15, n.2, p. 3-23, 2002.

BARDIN, L. Análise de conteúdo. 1ª Edição, São Paulo: Edições 70, 2011.

BERTERO, C.O.; CALDAS, M.P.; WOOD, T. Produção científica em administração de empresas: provocações, insinuações e contribuições para um debate. Revista de Administração Contemporânea, Curitiba, v.3, n.1, p. 147-178, 1999.

BIANCHETTI, L.; MACHADO, A. Trabalho docente no stricto sensu: publicar ou perecer? In: FIDALGO, F.; OLIVEIRA, M.A.; FIDALGO, N. (Orgs.). A intensificação do trabalho professor - tecnologias e produtividade. Campinas, SP: Papirus, 2009. p. 49-90.

BORBA, J. A.; MURCIA, F. Possibilidades de inserção da pesquisa contábil brasileira no cenário internacional: uma proposta de avaliação dos periódicos científicos de Contabilidade e Auditoria publicados em Língua Inglesa e disponibilizados no portal de periódicos da CAPES. In: ENCONTRO da ANPAD (XXX EnAnpad), 2006, Salvador. Anais... Salvador, BA, Brasil, 2006.

BOTOMÉ, S. P. Avaliação entre pares na ciência e na academia: aspectos clandestinos de um julgamento nem sempre científico, acadêmico ou de avaliação. Psicologia USP, São Paulo, v.22, n.2. 2011.

CAMPANARIO, J. M. El sistema de revisión por expertos (peer review): muchos problemas y pocas soluciones. Revista Espanhola de Documentação Científica, Madri, v.25, n.3, p. 166-184, 2002.

CARVALHO, Y.; MANOEL, E.J. Para além dos indicadores de avaliação da produção intelectual na grande área da saúde. Movimento, Porto Alegre, v.12, n.3, 193-225, 2006. 
DANTAS, D. C. A revisão por pares a partir da contribuição da hermenêutica

de Gadamer: um estudo em revistas de Administração do Brasil e da Colômbia. 2014. Tese (Doutorado em Administração) - Programa de PósGraduação em Administração, Pontifícia Universidade Católica de Minas Gerais, Minas Gerais, 2014.

EISENHARDT, K. M. Building Theories from Case Study Research. Academy of Management Review, Nova lorque, v.14, n.4, p. 532-550, 1989.

FREITAS, M. O pesquisador hoje: entre o artesanato intelectual e a produção em série. Cadernos Ebape.br, Rio de Janeiro, v.9, n.1, p. 1.158$1.163,2011$.

GABLOT, G. Qu'est-ce qu'un périodique scientifique? Bulletin des Bibliothèques de France, França, v. 29, n. 5, p. 384-387, 1984.

GIBBS, G. Análise de dados qualitativos. Porto Alegre: Artmed, 2009.

GODOI, C. K.; BALSINI, C. P. V. A metodologia qualitativa em estudos organizacionais. In: ENCONTROS DE ESTUDOS ORGANIZACIONAIS (ENEO), 2004, Atibaia. Anais... Rio de Janeiro, RJ, Brasil, 2004.

GODOI, C. K.; BANDEIRA DE MELLO, R.; SILVA, A. B. Pesquisa qualitativa em estudos organizacionais: paradigmas, estratégias e métodos. $1^{\text {a }}$ Edição, São Paulo: Ed. Saraiva, 2007.

GODOI, C; XAVIER, W. O produtivismo e suas anomalias. Cadernos Ebape. br, Rio de Janeiro, v.10, n.2, p. 456-465, 2012.

HAMES, I. 0 estado atual de revisão por pares: críticas, desafios e inovações. Ata de Reunião da Associação Brasileira de Editores Científicos, Rio de Janeiro, 2012.

KIRSCHBAUM, C.; PORTO, E.C.; FERREIRA, F.C.M. Neo-Institucionalização na produção acadêmica em Administração, Revista de Administração de Empresas, São Paulo, v. 3, n. 1, p. 1-16, 2004. 
KOSTOFF, R.N. Performance measures for government-sponsored research: overview and background. Scientometrics, Holanda, v. 36, n. 3, p. 281-292, 1996.

KRUGER, H. Avaliação de trabalhos científicos. Organizações \& Sociedade, Salvador, v.12, n.33, p. 179-182, 2005.

KUENZER, A.Z.; MORAES, M.C.M. Temas e tramas na Pós-Graduação em Educação. Educação \& Sociedade, Campinas, v.93, n.26, p. 1.341-1.362, 2005.

LEE, K.; BERO, L. What authors, editors and reviewers should do to improve peer review. Nature: International weekly journal of science, London: Nature Publishing Group, 2006. Disponivel em: < http://www.nature.com/ nature/peerreview/debate/nature05007.html> . Acesso em 13 out. 2016.

LEITE, N.; KNIESS, C.; RODRIGUES, A.; MACCARI, E. A ética na produção, orientação, submissão, avaliação e publicação científica: quem assume a responsabilidade? In: ENCONTRO DE ENSINO E PESQUISA EM ADMINISTRAÇÃO E CONTABILIDADE (ENEPQ), 2011, Paraíba. Anais... Paraíba, Brasil, 2011.

MACCARI, E.A.; RODRIGUES, L.C.; ALESSIO, E.M.; QUONIAM, L.M. Sistema de avaliação da pós-graduação da Capes: pesquisa-ação em um programa de pós-graduação em Administração. Revista Brasileira de Pós-Graduação, Brasília, v.9, n.5, 171-205, 2008.

MACEDO, Elizabeth. Cultura performativa e pesquisas em educação: desafios para a ação política. Cadernos de Pesquisa, São Paulo, v. 45, n. 158, 2015.

MASCARENHAS, A.; ZAMBALDI, F.; MORAES, E. Rigor, relevância e desafios da academia em Administração: tensões entre pesquisa e formação profissional. Revista de Administração de Empresas, São Paulo, v.51, n.3, p. 265-279, 2011.

MATTOS, P.L. Nós e os índices - a propósito da pressão institucional por publicação. Revista de Administração de Empresas, São Paulo, v.48, n.2, 144-149, 2008. 
MATTOS, P.L. Pés de barro do texto "produtivista" na academia. Revista de Administração de Empresas, São Paulo, v.52, n.5, p. 566-573, 2012.

MEDIA, M. M. Peer review in scholarly journals: Perspective of the scholarly community - an international study. Publishing Research Consortium, v. 28, n. 2, 2008.

MENEGHINI, R.; FONSECA, L. Índices alternativos de avaliação da produção científica em bioquímica no Brasil. Ciência e Cultura, São Paulo, v.42, n.9, p. 629-646, 1990.

MELLO, C.; CRUBELLATE, J.; ROSSONI, L. Redes de coautorias entre professores de programas brasileiros de pós-graduação (stricto sensu) em Administração: aspectos estruturais e dinâmica de relacionamento. Revista de Administração Mackenzie, São Paulo, v.10, n.5, 130-153, 2009.

MILLER, C. Peer review in the organizational and management sciences: prevalence and effects of reviewer hostility, bias, and dissensus. Academy of Management Journal, Nova lorque, v.49, n.3, p. 425-431, 2006.

MINAYO, M.C.S.; DESLANDES, S.F.; NETO, O.C.; GOMES, R. Teoria, Método e Criatividade. 18. ed. Petrópolis: Vozes, 1999.

MOREIRA, A.F.A. A Cultura da performatividade e a avaliação da PósGraduação em Educação no Brasil. Educação em Revista, Belo Horizonte, v.25, n.3, p. 23-42, 2009.

MULLIGAN, A.; HALL, L.; RAPHAEL, E. Peer Review in a Changing World: An International Study Measuring the Attitudes of Researchers. Journal of the American society for information science and technology, Carolina do Norte, v.64, n. 1, 2013.

NASCIMENTO, L.F. Modelo Capes de avaliação: quais as consequências para o triênio 2010-2012? Administração: Ensino e Pesquisa (RAEP), Rio de Janeiro, v.4, n.11, p. 579-600, 2010.

OMOTE S. Revisão por pares na revista brasileira de educação especial. Revista Brasileira de Educação Especial, Marília, v.11, n.3, p. 323-324, 2005. 
PAAVILAINEN, R.; ASTED, P. Self-reported family health and well being after early discharge from maternity hospital: a phenomenological study. Journal of Advanced Nursing, Reino Unido, v. 26, n. 2, p. 266-272, 1997.

PARTIS, M. Hope in homeless people: a phenomenological study. Primary Health Care Research and Development, Reino Unido, v. 4, n. 1, p. 9-19, 2003.

PATRUS, R.; DANTAS, D.; SHIGAKI, H. Pesquisar é Preciso, Publicar não é Preciso: História e Controvérsias sobre a Avaliação Por Pares. In: ENCONTRO DE ENSINO E PESQUISA EM ADMINISTRAÇÃO E CONTABILIDADE (ENENPQ), 4., 2013, Brasília. Anais... Brasília, DF, Brasil, 2013.

PATRUS, R.; LIMA, M. Entre a Formação de Professores e de Pesquisadores nos Programas de Pós-Graduação Strito Sensu em Administração: Contradições e Alternativas. In: ENCONTRO DA ANPAD (XXXVI EnANPAD), 2012, Rio de Janeiro. Anais... Rio de Janeiro, RJ, Brasil, 2012.

PINHO, J. A. G. Brevíssimo manual do editor: considerações sobre submissão e avaliação de artigos, o papel dos pareceristas e do editor de revistas científicas. Organizações \& Sociedade, Salvador, v.12, n.34, p. 169-173, 2005.

PESSANHA, C. Critérios editoriais de avaliação científica: notas para discussão. Revista Ciências da Informação, Brasília, v.27, n.2, p. 226229, 1998.

POUPART, J. et al. A pesquisa qualitativa: enfoque epistemológicos e metodológicos. 3. ed. Petrópolis: Editora vozes, 2002.

ROSA, A. "Nós e os índices" - um outro olhar sobre a pressão institucional por publicação. Revista de Administração de Empresas, São Paulo, v.48, n.4, p. 108-114, 2008.

RODRIGUES, L.O.C. Publicar mais, ou melhor? O Tamanduá Olímpico. Revista Brasileira de Ciência e Esporte, Florianópolis, v.29, n.1, p. 35-48, 2007. 
SALO, P.; HEIKKINEN, H. Slow science: an alternative to macdonaldization of the academic lifestyle. 2011. Disponivel em: < https://threerottenpotatoes. files.wordpress.com/2012/02/salo2011_slow-science-alternative-tomacdonaldization.pdf>. Acesso em 13 out. 2016.

SANDERS, P. Phenomenology: a new way of viewing organizational research. Academy of Management Review, Nova lorque, v. 7, n.3, p. 353-360, 1982.

SANTOS, L. Formação de professores na cultura do desempenho. Educação \& Sociedade, Campinas, v.25, n.89 1.145-1.157, 2004.

SCHWARTZMAN, Simon. Publicar ou morrer. 2013. Disponível em: <http:// www.schwartzman.org.br/sitesimon/?p=4777\&lang=en-us>. Acesso em: 15 set. 2016.

SERRA, F. A. R.; FIATES G. G.; FERREIRA, M. P. Publicar é difícil ou faltam competências? O desafio de pesquisar e publicar em revistas científicas na visão de editores e revisores internacionais. Revista de Administração Mackenzie, São Paulo, v.9, n.4, p. 32-55, 2008.

SGUISSARDI, V. A avaliação defensiva no "modelo Capes de avaliação": é possível conciliar avaliação educativa com processos de regulação e controle do Estado? Perspectiva, Florianópolis, v.24, n.1, p. 49-88, 2006.

SGUISSARDI, V. Produtivismo acadêmico. In: OLIVEIRA, D. A.; DUARTE, A.; VIEIRA, L. (Orgs.). Dicionário de Trabalho, Profissão e Condição do Professor. Belo Horizonte: Faculdade de Educação/UFMG, 2010.

SHIGAKI, H.B.; PATRUS, R. O papel da produção intelectual no sistema de avaliação dos programas de Administração pela Capes. Teoria e Prática em Administração, João Pessoa, v.2, n.2, p. 26-150, 2012.

STUMPF, I. Avaliação pelos pares nas revistas de comunicação: visão dos editores, autores e avaliadores. Perspectivas em Ciência da Informação, Belo Horizonte, v.13, n.1, p. 18-32, 2008. 
THIRY-CHERQUES, H. R. Comentando: "A face oculta do parecerista: discussões éticas sobre o processo de avaliação de mérito de trabalhos científicos". Organizações \& Sociedade, Salvador, v.12, n.32, p. 169-172, 2005.

TREIN, E.; RODRIGUES, J. O mal-estar na academia: produtivismo científico, o fetichismo do conhecimento mercadoria. Revista Brasileira de Educação, Rio de Janeiro, v.16, n.48, p. 769-819, 2011.

VELHO, G. As ciências sociais nos últimos 20 anos: três perspectivas. Revista Brasileira de Ciências Sociais, São Paulo, v. 12, n. 35, p. 1-18, 1997.

ZUCKERMAN, H.; MERTON, R.K. Patterns of evaluation in science: institutionalization, structure and function of the referee system. Minerva, Holanda, v. 9, p. 66-100, 1971.

WARE, M. Peer review: benefits, perceptions and alternatives. Publishing

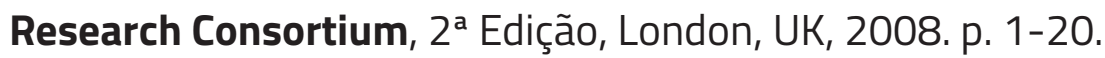

YAFFE, M.B. Re-reviewing peer review. Nature: International weekly journal of science. London: Nature Publishing Group, 2009. Disponivel em:< http:// stke.sciencemag.org/content/2/85/eg11>. Acesso em 13 out. 2016.

Recebido em 11/04/2016

Aprovado em 21/09/2016 